\title{
Production of Market Bag and their Stability and Optimization Parameters
}

\author{
Pelin Alcan ${ }^{1 *}$, Hamdi Sözöz ${ }^{2}$ and Samet Burçin Aydoğmuş ${ }^{3}$ \\ Istanbul Gelisim University, Faculty of Engineering and Architecture, Industrial \\ Engineering, Avcilar, Istanbul \\ Istanbul Gelisim University, Faculty of Engineering and Architecture, \\ Mechatronic Engineering, Avcilar, Istanbul \\ Marmara University, Institute of Science, Machine Training Master Science, \\ Istanbul \\ *palcan@gelisim.edu.tr,hsozoz@gelisim.edu.tr
}

\begin{abstract}
It is well known that the plastic film materials are widely used in every area of our life. The reasons why the plastic films are used so widely are; they are light, can be manufactured easily and in series, are durable, their chemical features required for packing can be adjusted as it is wished and almost all the used products can be recycled and reused. The blown up film extrusion method can be defined as; melting of polymer materials in the heat level determined according to raw material type, passing of them from a circular mold, blowing up by means of pressurized air and then cooling process to convert them to a film form. Mainly, the molding system and heat treatment parameters affect the features of the film to be produced. For this reason, the treatment parameters and mold design must be optimized by means of computer programs to minimize the defects in production. In this work, we guided several experiments on the matter of stability to provide the desired properties using designed and manufactured three layer extruder film mold machine. An experimental study was carried out to investigate film stability changes due to the blow up and traction ratio parameters in blown up film production were examined and described in details. Two applications that we used had not been approached together although there were some works which were concerned about mold design and experimental analysis of the bubble stability in the literature. It was intended improving the quality of the final product with both of design and production factors were handled together in this study.
\end{abstract}

Keywords: blown film, molten plastic, extrusion system, mold machine, heat treatment, film stability

\section{Introduction}

The blown film extrusion system is one of the most complex and sensitive of all plastics processing technologies. Even though these may be known well enough, there are some other factors to be considered in production like; the way molten plastic flow on the screw barrel, die cavity, velocity of the flow, pressure and temperature all affect the inner structure of the film and its surface properties.

In the literature, Prakash (2006) interested in defects in multilayer plastic films in the extrusion process in his paper. For this reason, a methodology to link process parameters and fluid-rheology to onset of certain types of defects was improved. The defects related to interface slipped and instabilities at the interface in the response to flow perturbations

${ }^{*}$ Corresponding Author 
or local disturbances. Also, Prakash and Moitra (2006) discussed predictions and control of defects that may form in multilayer plastic films as the constituent materials pass through a co-extrusion die. A method for improving a robust process was introduced for elimination of these defects. The stability of the double components two-layer blown film coextrusion process had been examined using a simple model in which the two layers consist of a Newtonian and an upper-convected Maxwell fluid (UCM), respectively. The final results of the linear stability analysis present that a critical value of the film thickness existed below which the flow becomes unstable (Yoon and Park, 2000).

According to the reports given in the different papers of Parakash (2006) and Zhang, Lodge and Macosko (2006), the failures of interface generally originated from variations of primary flow ratio, shear stresses which formed through layers, zigzags and the flow lines which arise on the film depending on the shear stresses and diversity of the flow speed, the flow features of the binder reasons. Errors that have formed in process should be analyzed by examining of these error values investigated. In the researches which had been done about these error values showed the solutions and causes of lines, zigzags and axial orientations which were on the films because of machine-die-raw material by Parakash (2006) and Zhang and Ajji (2005). Petkim Petryo-chemistry Turkish Company had examined the causes and the solutions of these error reasons. Zatloukal and Vlcek (2004), Muke and vd, (2003) and Yoon and Park (2000) had handled the die design analysis with the results of experimental investigations to test the die design eligibility, bubble stability and had realized the optimization of the process according to that. Moreover, Carneiro vd, (2008) and Zhang and Ajji (2005) had handled the thickness of the film and the factors that affect the thickness in their studies of stability experiment.

Experimental analysis was given in the second section of this paper. Then, general information about the film blowing up process and film blowing up machine were presented in the same section, following this, information about the raw materials and additives used in the film blowing up process and defects occur during the production phase were given. In the third section, experimental designs about the data indicated above were well described. Here, first of all, cause and effect diagram was realized in the light of the process variables involved in the literature and Taguchi method was analyzed. Then, administration of experiments was given in section four. ANOVA analysis and optimization parameters of the experimental results were examined in the fifth section. Finally, in the sixth and last section, final evaluations related to the results of the study were made and recommendations were given to improve the process of this work.

\section{Experimental Analysis}

Information concerning kind and quality of the polymer was used in blown film mold designing. In comparison of the amount production in the unit of time, thickness and width properties had to be known for production of the flow ratio of each molten raw material. To be used in different necessary flow sequences and the ratio of compression also varied.

In this study, we conducted several experiments on the matter of stability to obtain the desired properties using designed and manufactured three layer extruder film mold machine. Concerning stability experiments, we employed an extruder film machine with a screw diameter of $\emptyset 60 \mathrm{~mm}$ and that produce film with a width of $1500 \mathrm{~mm}$. The capacity of the machine was found to be approximately $200 \mathrm{~kg} / \mathrm{h}$. The mathematical equations used to determine the parameters of the design of the mold were determined using the mathematical equations as given below:

Balloon diameter : $\mathrm{D}_{\mathrm{x}}=0.6366 * \mathrm{RFW}$

Blowing up ratio : $\mathrm{BUR}=\mathrm{D}_{\mathrm{x}} / \mathrm{D}_{0}$

Traction up ratio : $\mathrm{TUR}=\mathrm{MC} / \mathrm{BUR} * \mathrm{t}$

Film unit weight : $\mathrm{G} / \mathrm{M}=\mathrm{t} * \mathrm{~d} * \mathrm{RFW} * 2$ 
Machine capacity : $\mathrm{C}=(\mathrm{V} * \mathrm{~T} * \mathrm{G}) \mathrm{M} * 1000$

Film thickness $: \mathrm{t}=\mathrm{MC} /(\mathrm{TUR} * \mathrm{BUR})$

$\mathrm{RFW}=$ Film roll width

$\mathrm{D}_{0}=$ Blow mold outlet diameter

$\mathrm{MC}=$ Mold cavity

$\mathrm{d}=$ Density

$\mathrm{V}=$ Traction velocity

$\mathrm{T}=$ Time

The experimental design of our study was based on Taguchi Experimental Design Technique. The steps that were given in this work as follows:

Step 1. Selection of factors and evaluation of their interaction with each other (cause and effect diagram),

Step 2. Determination of factor levels,

Step 3. Selection of correct balanced design,

Step 4. Matching of factors and/or their interaction between columns in the balanced design system,

Step 5. Realization of experiments as planned,

Step 6. Analysis and research papers of the outcomes obtained.

A multilayered film manufacturing process could be seen in Figure 1. Also, the film blowing mold with three layers was used in all experiments as shown in Figure 2.

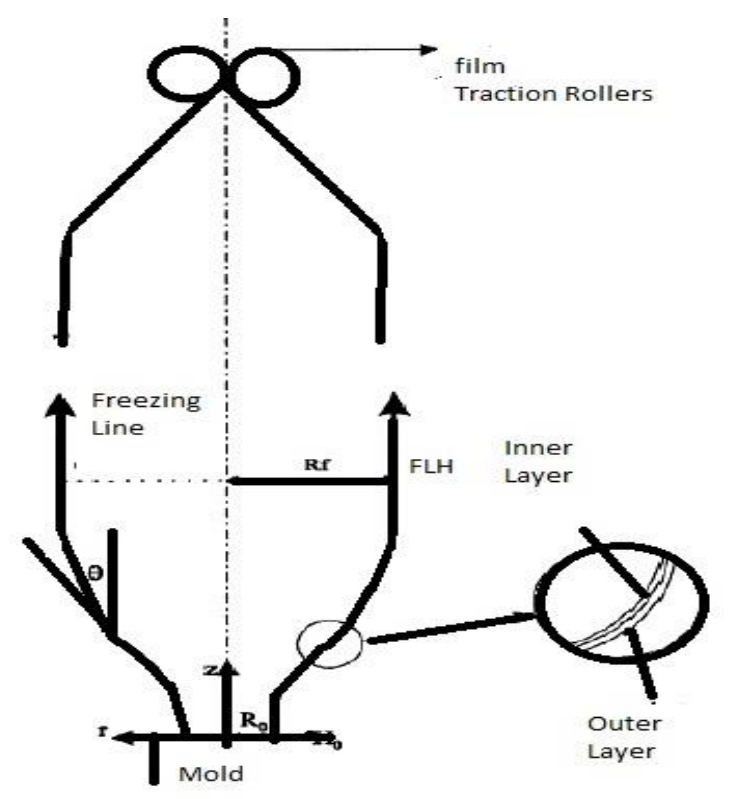

Figure 1. A Multilayered Film Manufacturing Process 


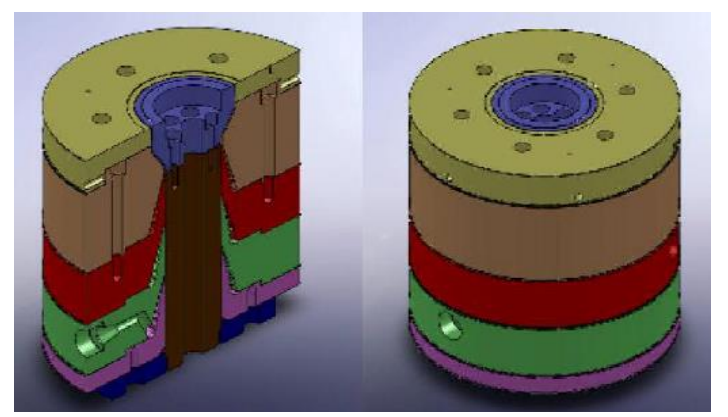

Figure 2. Using Film Blowing Mold with Three Layers in the Experiment

Assembly of film blowing mold with three layers in the experiment (in Figure 3.) and dismantling of film blowing mold with three layers (in Figure 4.) were represented below:

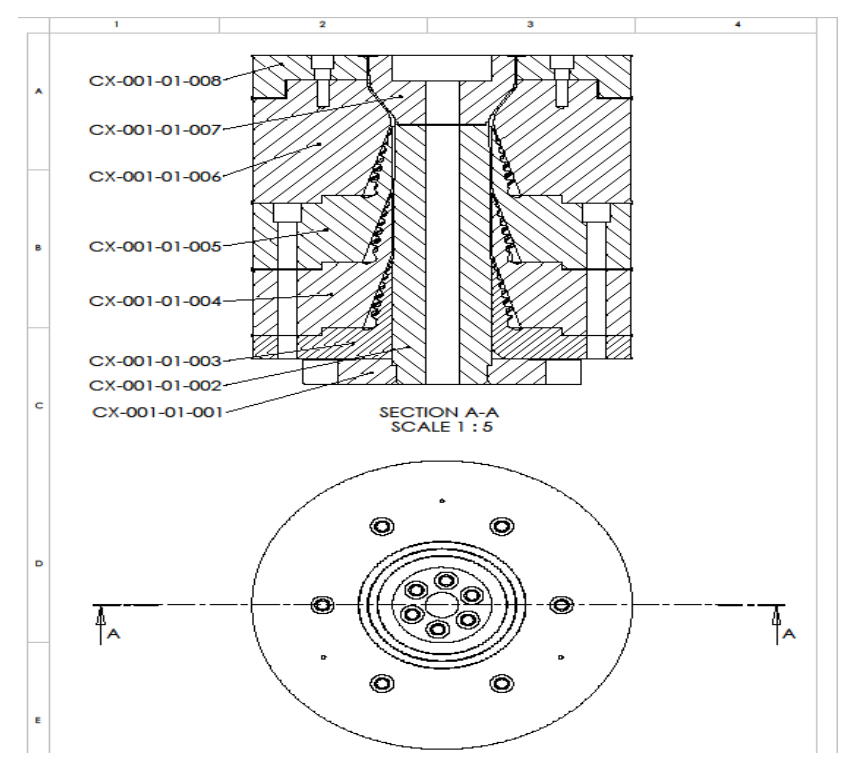

Figure 3. Using Assembly of Film Blowing Mold with Three Layers in the Experiment

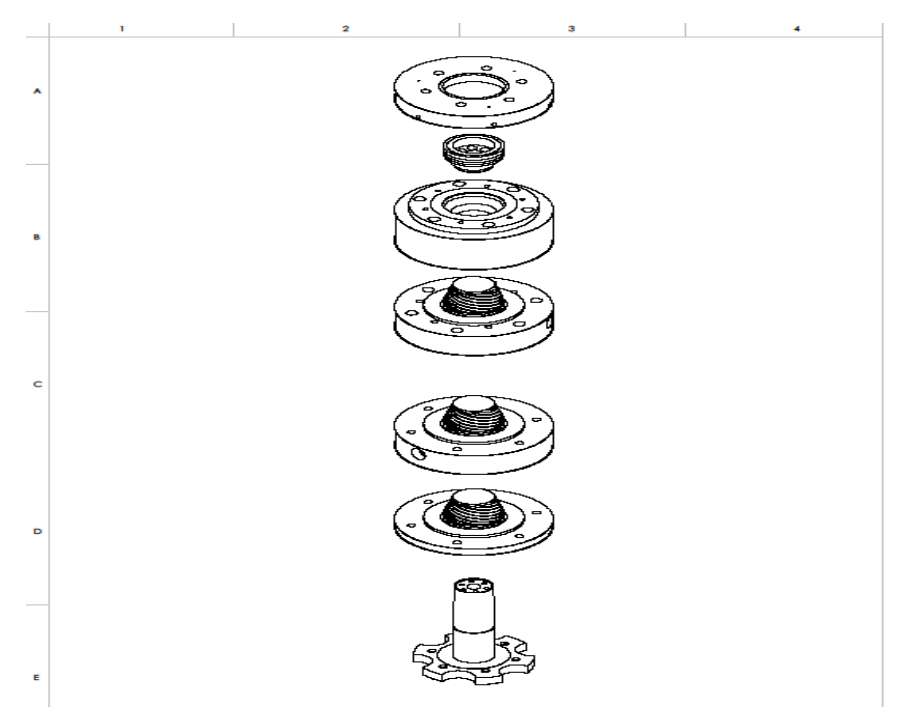

Figure 4. Dismantling of Film Blowing Mold with Three Layers 


\subsection{Machinery and Raw Materials Employed in the Experiment}

Film stability experiments were conducted using LDPE, LLDPE and EVA materials and an industrial machine with a screw diameter of $\varnothing 60 \mathrm{~mm}$ and that produced blow film with the width of maximum $1500 \mathrm{~mm}$. Technical properties of the machine and the raw material used in the experiment were showed as in Table 1 and Table 2:

Table 1. Technical Properties of the Machine used in the Experiment

\begin{tabular}{|l|l|}
\hline Kind of raw materials & LDPE, LLDPE, EVA \\
\hline Screw diameter & $\emptyset 60 \mathrm{~mm}$ \\
\hline L/D ratio & $24: 1$ \\
\hline Screw velocity & $72 \mathrm{rev} / \mathrm{min}$ \\
\hline Mold exit diameter & $\varnothing 180 \mathrm{~mm}$ \\
\hline Mold cavity & $1,5 \mathrm{~mm}$ \\
\hline Number of heat controllable zones & 6 \\
\hline
\end{tabular}

Table 2. Technical Properties of the Raw Material used in the Experiment

\begin{tabular}{|l|l|}
\hline Kind & LDPE \\
\hline Producer & SABIC \\
\hline Product code & $2004 \mathrm{TX} 37$ \\
\hline Density & $0,921 \mathrm{~g} / \mathrm{cm} 3$ \\
\hline Molten material ratio & $4,7 \mathrm{~g} / 10 \mathrm{~min}$ \\
\hline
\end{tabular}

\subsection{The Technical Properties of Machines Used in the Experimental Process}

The measurements were performed through a distance sensitive laser detector and infrared emitting instruments since measurements had to be carried out with contact-free distance and temperature devices during the experiment. Technical properties of these instruments were given in Table 3 and Table 4 as follow:

Table 3. Distance Measurement Instrument in Experiment

\begin{tabular}{|l|l|}
\hline Model & Up to NCDT ILR 1181 \\
\hline Distance detection & $0,1-150 \mathrm{~m}$ \\
\hline Time for distance detection & $20 \mathrm{~ms}$ \\
\hline Measured place display & Laser light \\
\hline
\end{tabular}

Table 4. Temperature Measurement Instrument in Experiment

\begin{tabular}{|l|l|}
\hline Model & Thermometer LS \\
\hline Measurement range & $150 \mathrm{~ms}$ \\
\hline Error ratio, heat detection time & $150 \mathrm{~ms}$ \\
\hline Focusing distance & $1-62 \mathrm{~mm}$ \\
\hline
\end{tabular}

\section{Schematic Design of Experimental Taguchi Method}

According to reported works by Muke vd (2003) and Zatloukal and Vlcek (2004), the factors that affect bubble thickness in bubble film blowing machines, were blown-up ratio (BUR) and traction-up ratio (TUR). While the experiments were performed in stabile state which kind of raw material should not be changed because stability of bubble thickness varies depending on the kind of the raw material used. In addition to the aforementioned, environmental factors like heat, humidity and air flow should be kept in stable. Bubble structures before and after deformation due to the air flow were shown in Figure 5. 

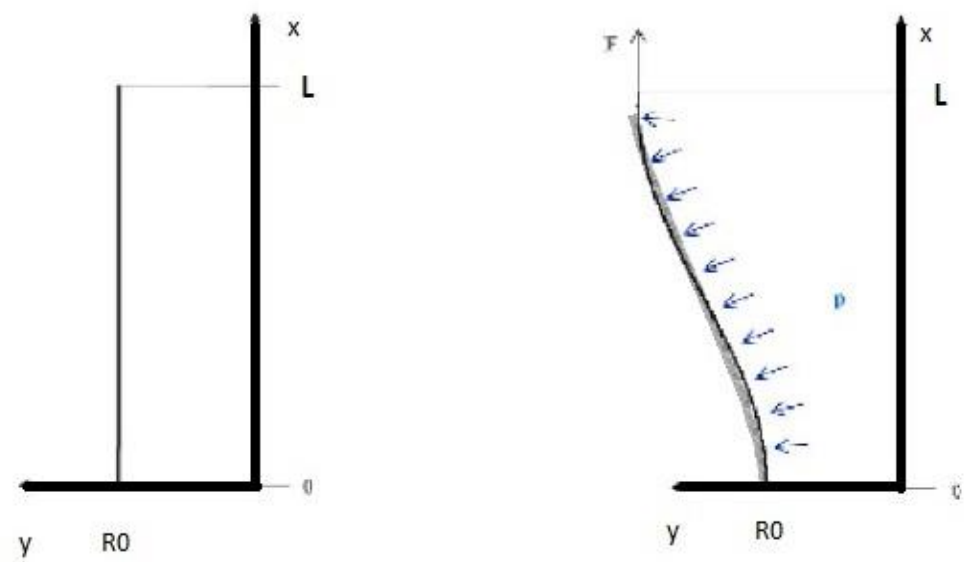

Figure 5. Bubble Structures before-after Deformation due to the Air Flow

Taking the factors to be used in the experiments and the conditions into consideration, it was deemed suitable to employ L9 Taguchi experiment system. Through this system, it was possible to reach the results aimed with one third (9 experiments instead of 27) of the experiments needed in complete factorial experimental design.

\subsection{Cause and Effect Diagram}

Fishbone diagram was one of the first employed in designing experiments. This diagram reveals whole factors, which represent the quality of the product or the quality of the processes, the measurements to be carried out and to evaluate all the factors which affect these values. Through the fishbone diagram, the factors were considered as variables and factors that were determined. As illustrated in Figure 6, the factors that affected the freezing point of bubbles were collected under four main headings. In this shape, all the factors should be kept in stable, except blown-up ratio and traction-up ratio, and the effect of these two factors should be studied further.
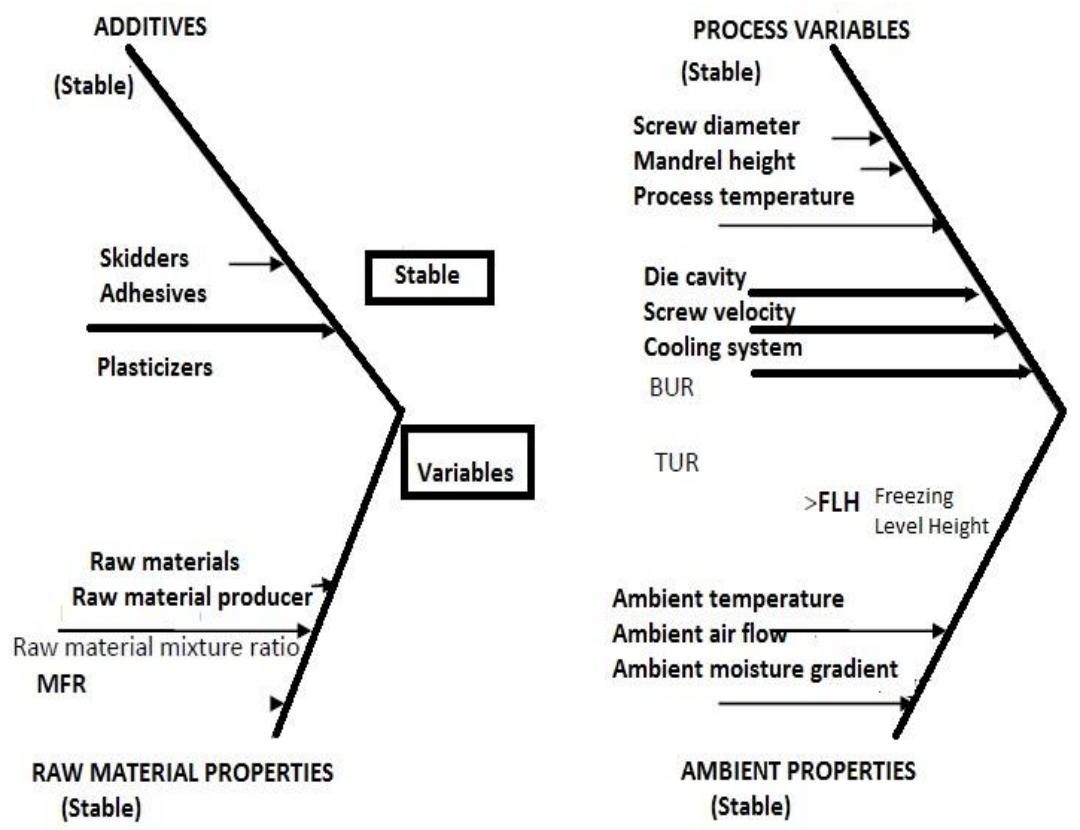

Figure 6. Cause and Effect Diagram 
It was rather important what measurement to be used in determining the effect of the both factors under the most balanced processing conditions and to determine the effect level of the two variables. In finding out what levels of the two variables those were determined upon studies in literature and through the examination of the cause and effect diagram to determine the effect of each factor, as well as what measurement to be used in stability evaluation was important. In the stability analysis studies, BUR (Blown up Ratio) and TUR (Traction up Ratio) values had been carried out as variable factors in determining freezing point height.

Upon determining the concerning the factors and their levels to be studied, the phase of determination of the experiments were concerned. The first data collected to determine the vertical lay out that had to be selected via Taguchi Experimental Design. The overall objective model was produced high quality product at low cost which was the total level of the total unconstraint. The unconstraint degree, in short terms, provide the necessary numbers to make a comparison between the design parameters and to find out what level should reveal optimum level.

For a three level factor, the unconstraint degree being two, the unconstraint degree that the chosen design should be higher than the four unconstraint degree needed for two factors. When evaluated from this point, the appropriate design was thought as Taguchi L9 with nine experiments. This design gives the chance to study the main effects of maximum four numbers of three level factors (maximum unconstraint degree of the total nine experiments allow the number of eight). The number of factors within the coverage of the experiment to be made was two, since the level number was three, unconstraint degree (apart from the necessary four unconstraint degree) the other unconstraint degrees were used in calculation of error value. The factors and the levels would be employed in the experiment were provided in Table 5 and in Taguchi L9 experimental design table, which were provided in Table 6.

Table 5. Experimental Factors and their levels

\begin{tabular}{|l|l|l|l|}
\hline Factors & Level 1 & Level 2 & Level 3 \\
\hline Blown up ratio (BUR) & 2,48 & 3 & 3,54 \\
\hline Traction up ratio (TUR) & 6,05 & 8,64 & 12,1 \\
\hline
\end{tabular}

Table 6. Experimental Design of Taguchi L9

\begin{tabular}{|l|l|l|}
\hline \multicolumn{3}{|c|}{ Factors \& their levels } \\
\hline & BUR & TUR \\
\hline Experiment No & Blow Ratio & Traction Ratio \\
\hline 1 & 1 & 1 \\
\hline 2 & 1 & 2 \\
\hline 3 & 1 & 3 \\
\hline 4 & 2 & 1 \\
\hline 5 & 2 & 2 \\
\hline 6 & 2 & 3 \\
\hline 7 & 3 & 1 \\
\hline 8 & 3 & 2 \\
\hline 9 & 3 & 3 \\
\hline
\end{tabular}

The criterion used in measuring and evaluating the properties of quality in experimental design of Taguchi, was determined to be ratio of the signal measured (S) and the noise $(\mathrm{N})$. The signal value and the undesired outcome of the system was corresponded the real value to be measured.

It was also so important to obtain the characteristic experimental target of quality value in calculation of signal/noise ratio. Here, three fundamental categories were given as follows: 
- The lowest value was good (the target was reached to the lowest value)

- The high value was good (the target was reached to the highest value)

- The Nominal value was good (the target was reached to the nominal value)

In this study, since the film was to be cooled before the film was coiled which has to be very cool so, the FLH value should be as low as possible. For this reason, it would be used the lowest value approach in $\mathrm{S} / \mathrm{N}$ ratio. The equation used in this approach was given as below:

$\eta=-10 \log _{10}\left[\frac{1}{n * \sum_{i=1}^{n} y_{i}^{2}}\right]$

\section{The Processes of the Experiments}

Through the help of cause and effect diagram and the studies of the literature, the experimental combinations were determined based on the combination of established variables. It was used experimental measurement devices and raw material which was realized in congruence with the Taguchi L9 system, whose properties have been previously mentioned. During the experiment, the screw speed was chosen as $58 \mathrm{rev} / \mathrm{min}$. In order to melt and homogenize the raw material to be used, the necessary heat was obtained through the resistant placed in different pats. The heated parts, in order, were; barrel 1, barrel 2, barrel 3, strainer unit, material entrance and the blowing die. Measurements carried out through the contactless heat sensors in different parts were respectively; $142^{\circ} \mathrm{C}, 157^{\circ} \mathrm{C}, 166^{\circ} \mathrm{C}, 140^{\circ} \mathrm{C}, 137^{\circ} \mathrm{C}$ and $170^{\circ} \mathrm{C}$. The experiments performed determination of freezing height line was achieved through a contactless distance measuring instrument and a fixing apparatus. The freezing point heights for every experimental conditions was repeated five times and the averages of these values were taken into consideration. In this way, the reliability of the results were ensured statistically. Depending on these outputs and through the experiments performed, the values of the freezing height line used for the bubble stability determination had been established. Combinations of experiments and the final values of the experiments with these combinations were shown in Table 7.

Table 7. Experimental Results According to the Experimental Design

\begin{tabular}{|c|c|c|c|}
\hline Experiment No & BUR & TUR & FLH (mm) \\
\hline 1 & 2,48 & 6,05 & 246 \\
\hline 2 & 2,48 & 8,64 & 249 \\
\hline 3 & 2,48 & 12,10 & 257 \\
\hline 4 & 3,00 & 6,05 & 226 \\
\hline 5 & 3,00 & 8,64 & 231 \\
\hline 6 & 3,00 & 12.10 & 244 \\
\hline 7 & 3,54 & 6,05 & 216 \\
\hline 8 & 3,54 & 8,64 & 212 \\
\hline 9 & 3,54 & 3,54 & 232 \\
\hline
\end{tabular}

The FLH values were used obtained following these experimental data in calculation of $\mathrm{S} / \mathrm{N}$ ratio, variation analysis and optimization of operating value. Minitab 15 statistical analysis program was used in these analysis processes. In order to crosscheck, theoretically, the value obtained the thickness of the film was measured. The values of the measurements obtained were given in Table 4. When obtained results of the film thickness were examined through the equation of $t=$ MC/TUR $\times$ BUR. The results almost coincided with the following equations segments: 
MC : Stands for mold cavity

TUR : traction up ratio of the film

BUR : blowing up ratio of the film

$\mathrm{T}$ : film thickness

In addition; changes in film thicknesses in accordance with the traction and the blowing ratios were shown in Table 8, Figure 7 and Figure 8.

Table 8. Experimental and Theoretical Film Thicknesses

\begin{tabular}{|c|c|c|c|c|}
\hline Experiment No & BUR & TUR & $\mathrm{t}(\mathrm{mm})$ Experimental & $\mathrm{t}(\mathrm{mm})$ Theoretical \\
\hline 1 & 2,48 & 6,05 & 0,100 & 0,099 \\
\hline 2 & 2,48 & 8,64 & 0,070 & 0,070 \\
\hline 3 & 2,48 & 12,1 & 0,050 & 0,049 \\
\hline 4 & 3,00 & 6,05 & 0,083 & 0,082 \\
\hline 5 & 3,00 & 8,64 & 0,058 & 0,057 \\
\hline 6 & 3,00 & 12.1 & 0,041 & 0,041 \\
\hline 7 & 3,54 & 6,05 & 0,070 & 0,070 \\
\hline 8 & 3,54 & 8,64 & 0,050 & 0,050 \\
\hline 9 & 3,54 & 12,1 & 0,035 & 0,035 \\
\hline
\end{tabular}

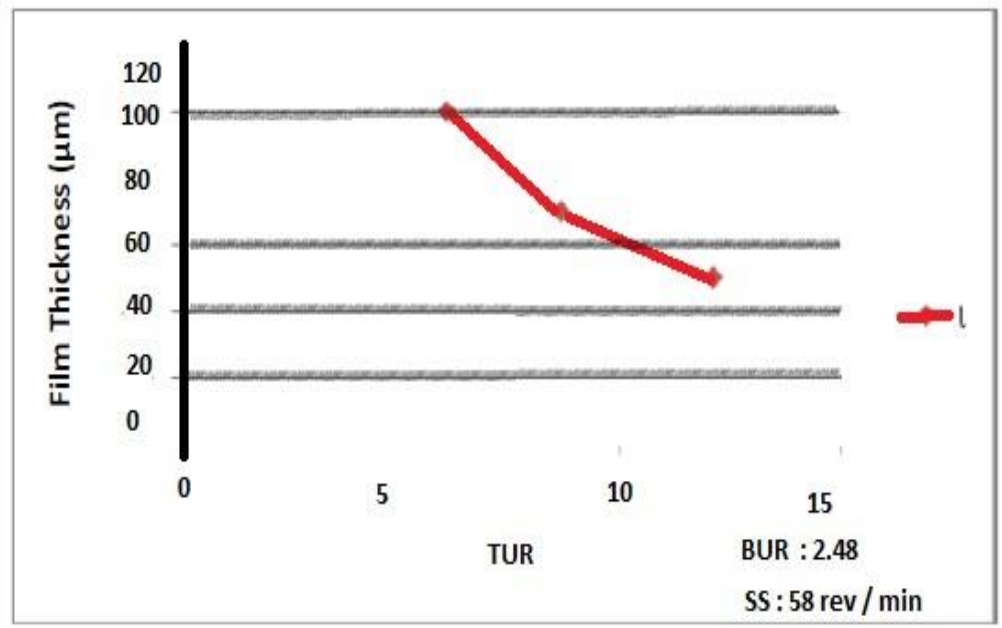

Figure 7. While BUR is 2.48, Film Thickness Change in Comparison to TUR

\section{Variation Analysis (ANOVA)}

First of all, the effects of each factor should be investigated at every level. For this reason, the averages of $\mathrm{S} / \mathrm{N}$ ratios calculated were handled separately in Table 9 for every level of each factor. For example, determining the ratio of the first level, whose traction ratio was 6.05 , the averages of $\mathrm{S} / \mathrm{N}$ ratios were taken for the first experiment, the fourth experiment and the seventh experiment. Also, the average numbers of $\mathrm{S} / \mathrm{N}$ ratios of the nine experiments were calculated. The following equation was used for this purpose:

$\eta_{\mathrm{m}}=1 / \mathrm{n} * \sum_{\mathrm{i}=1}^{\mathrm{n}} \mathrm{y}_{\mathrm{i}}$

As a result of these calculations, the highest ratio of Signal/Noise was indicated to the best result of the experiment. In other words, it signed to the lowest result of the experiment (the height of the freezing line was the minimum value). These values provided respectively were shown for each factor as in Figure 9 with several graphics. Starting from the ratios of N/S calculations, variance analysis should be achieved for the final optimization. 
Table 9. S/N Ratios Obtained as the Result of Experiments

\begin{tabular}{|c|c|c|c|c|}
\hline Experiment No & BUR & TUR & FLH $(\mathrm{mm})$ & S/N Ratio $(\mathrm{dB})$ \\
\hline 1 & 2,48 & 6,05 & 246 & $-47,8187$ \\
\hline 2 & 2,48 & 8,64 & 249 & $-417,9240$ \\
\hline 3 & 2,48 & 12,10 & 257 & $-48,1987$ \\
\hline 4 & 3,00 & 6,05 & 226 & $-47,0822$ \\
\hline 5 & 3,00 & 8,64 & 231 & $-47,2722$ \\
\hline 6 & 3,00 & 12.10 & 244 & -477478 \\
\hline 7 & 3,54 & 6,05 & 216 & $-46,6891$ \\
\hline 8 & 3,54 & 8,64 & 212 & $-46,5267$ \\
\hline 9 & 3,54 & 3,54 & 232 & $-47,3098$ \\
\hline
\end{tabular}

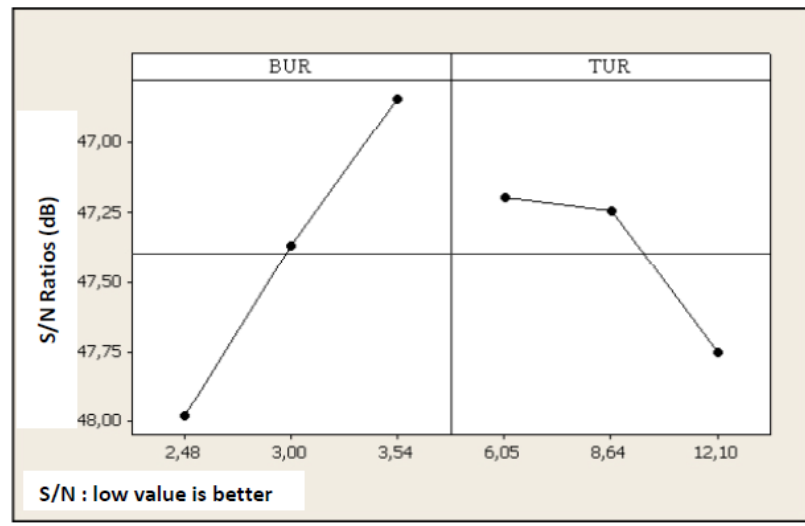

\section{Figure 9. S/N Ratios for the Ratios of Blow and the Ratios of Traction}

The goal of the variation analysis was to find out the chosen degree of the output (the height of the freezing point) affected the quality and how the different levels caused to the alteration. Besides, the reliability of the results obtained was statistically tested. For this purpose, $\mathrm{SS}_{\mathrm{t}}$ value (sum of the total squares) indicated the total variability of $\mathrm{S} / \mathrm{N}$ ratio was calculated as the following equation:

$S S_{t}=\sum_{i=1}^{n}\left(\eta_{i}-\eta_{m}\right)^{2}$

$\eta_{i}=$ the ratio of $S / N$ calculated with the help of measuring of the cutting strength

$\eta_{\mathrm{m}}=$ the average of the ratio of $\mathrm{S} / \mathrm{N}$ calculated with the help of measuring of the cutting strength

$\mathrm{n}=$ total number of the experiments.

The value of $\mathrm{SS}_{\mathrm{t}}$ was occurred with the sum of the values of $\mathrm{SS}_{\mathrm{A}}, \mathrm{SS}_{\mathrm{B}}$ (separately the sum of squares of each factors) and $\mathrm{SS}_{\mathrm{C}}$ (the sum of squares of the tolerance). The equation of the sum of squares for each factor was shown as follows:

$S S_{A}=\sum_{i=1}^{k_{A}}\left[\mathrm{\eta}_{A i} *\left(\mathrm{\eta}_{A}-\mathrm{\eta}_{m}\right)^{2}\right]$

$\mathrm{k}_{\mathrm{A}}=$ The number of levels of the factor $\mathrm{A}$

$\eta_{\mathrm{Ai}}=$ The number of the experiments of the factor A on the level of $i$

$\eta_{\mathrm{A}}=$ The ratio of $\mathrm{S} / \mathrm{N}$ of the factor $\mathrm{A}$ on the level of $i$

In the next step, F-test was applied to show the each factor of the experiment which how affects the results of the experiments. For this reason, firstly, the value of the sum of the squares mean should be calculated. This value was founded with the division of the value of the sum of the squares mean and the degree of unconstraint. Also, the value of $F$ was obtained that the value of the sum of the squares mean was divided to the value of the error of the sum of the squares mean (For example, the number of 0.974 divided to the 
number of 0.021 for the factor of BUR on Table 10). The sum of the squares mean of related factor divided to the total number of the whole squares then we could find how affected the effectiveness of the factor to the stability with the ratio of percent (For instance, the value of 1.948 divided to the value of 2.602 for the factor of BUR on Table $10)$.

Table 10. ANOVA Table in Congruence with Taguchi L9 Experiment Design

\begin{tabular}{|l|c|l|l|l|l|l|l|l|l|}
\hline & \multirow{2}{*}{$\begin{array}{l}\text { Degree } \\
\text { of } \\
\text { freedom }\end{array}$} & \multicolumn{2}{|l|}{ Average S/N ratios (dB) } & $\begin{array}{l}\text { Sum of } \\
\text { squares } \\
1\end{array}$ & $\begin{array}{l}\text { Level } \\
2\end{array}$ & $\begin{array}{l}\text { Level } \\
3\end{array}$ & $\begin{array}{l}\text { Average } \\
\text { sum of } \\
\text { squares }\end{array}$ & $\begin{array}{l}\text { Factor } \\
\text { effect } \\
\%\end{array}$ & Failure \\
\hline $\begin{array}{l}\text { Blow up } \\
\text { ratio } \\
\text { (BUR) }\end{array}$ & 1 & $-47,98$ & $-47,37$ & $-46,84$ & 1,14 & 1,948 & 0,974 & 74,89 & 47,53 \\
\hline $\begin{array}{l}\text { Traction } \\
\text { up ratio } \\
\text { (TUR) }\end{array}$ & 2 & $-47,2$ & $-47,24$ & $-47,75$ & 0,56 & 0,572 & 0,286 & 21,97 & 13,94 \\
\hline Failure & 4 & & & & & 0,082 & 0,021 & 3,15 & \\
\hline Total & 8 & & & & & 2,602 & & 100 & \\
\hline
\end{tabular}

\subsection{Optimization of Parameters According to the Experimental Results}

As it could be seen in the graphics in Figure 9, the highest level of the ratio of $\mathrm{S} / \mathrm{N}$ was the number of 3,54 in blowing up ratios and also the ratio of traction velocity was the number of 6,05. As optimum point, the recommended combinations were; the ratio of blowing was 3,54 and the ratio of traction force was 6,05. Optimization experiments should be done based on these values. The data used in the experiment and the freezing line height obtained following optimization experiment was given in Table 11 as follows:

\section{Table 11. Values Obtained Optimization and Approval Methods with Taguchi Experimental Analysis}

\begin{tabular}{|c|c|c|}
\hline \multicolumn{3}{|l|}{ Optimum Levels } \\
\hline & Level & Value \\
\hline Blowing up Ratio (BUR) & 3 & 3,54 \\
\hline Traction up Ratio (TUR) & 1 & 6,05 \\
\hline Calculated S/N Ratio & & $-45,64$ \\
\hline Optimum Freezing Point Height (calculated) & & $214,56 \mathrm{~mm}$ \\
\hline Optimum Freezing Point Height (experimental) & & $215 \mathrm{~mm}$ \\
\hline
\end{tabular}

\section{Conclusion}

In this work, chemical and physical properties of the plastic products optimized and it used for packaging, carrying, and shipping as greenhouse coverings. It was very well known the properties of the raw materials used, the machines employed and the necessary mold system to achieve by the optimum conditions. Even though these information should be known perfectly, there were some other factors to be considered in the production like; the way molten plastic flow in the screw barrel, die cavity, velocity of flow, pressure and temperature all affect the inner structure of the film and its surface properties.

In this article, while the mold designing is in process, a machine with the maximum diameter of $60 \mathrm{~mm}$ and the maximum width of $1500 \mathrm{~mm}$ found in the average values of the machines and molds are being produced. Thus, the tripled inflated film machine's capacity of average weight per time is $200 \mathrm{~kg} / \mathrm{h}$.

The blown up ratio and traction velocity ratio were found to be 3.54 and 6.05 respectively which indicate the optimum values after the experiment. These values were calculated from the experimental results therefore these values are congruence with the 
optimum conditions. $\mathrm{S} / \mathrm{N}$ ratio was found as $-46.64 \mathrm{db}$, also the height of the optimum freezing point, theoretically, was found as $214.56 \mathrm{~mm}$. Determination of the optimum values should not only decrease the number of the failures in production, performance and the development of the quality but also contribute towards cutting of production costs as well. These two applications had not been approached together although there were some works which were concerned about mold design and experimental analysis of the bubble stability in the literature. In this study, it was intended improving the quality of the final product with both of design and production factors were handled together. The factors affected to the film stability were examined during the process of the manufacturing. The optimum working conditions were determined according to the composition of the available mold, machine and raw materials.

Machines worked with completely automation systems should be used to increase the stability and the quality of the product at all of these systems. Thus we thought that product defects and process instabilities which could be after fitting errors should be removed.

\section{References}

[1] O. Parakash, "Defects inmultilayerplastic films I: Interface defects in extrusion", Computational Materials Science, vol. 37, (2006), pp. 7-11.

[2] O. Parakash and A. Moitra, "Defects in multilayerplastic films II: Streak formation in extruded films", Computational Materials Science, vol. 37, (2006), pp. 12-14.

[3] K. S. Yoon and C. W. Park, "Stability of a two-layer blown film co-extrusion", J. Non-Newtonian Fluid Mechanic, vol. 89, (2000), pp. 97-116.

[4] S. Muke, H. Connel, I. Sbarski and S. N. Bahattacharya, "Numericalmodeling and experimental verification of blown film processing", Journal of Non-Newtonian Fluid Mechanic, vol. 116, (2003), pp. 113-138.

[5] M. Zatloukal and J. Vlcek, "Modeling of the film blowing process by using variation Principles", Journal of Non-Newtonian Fluid Mechanic, vol. 123, (2004), pp. 201-213.

[6] O. S. Carneiro, R. Reis and J. A. Covas, "Small-scale production of coextruded biaxial Oriented blown film", Polymer Testing, vol. 27, (2008), pp. 527-537.

[7] X. M. Zhang and A. Ajji, "Oriented structure of PP/LLDPE multilayer and blends films", Polymer, vol. 46, (2005), pp. 3385-3393.

[8] J. Zhang, T. P. Lodge and C. W. Macosko, "Interfacial Slip Reduces Polymer-Polymer Adhesion During Coextrusion", The Society of Rheology, vol. 50, (2006), 41-57. 